\title{
The Discourse of Climate Change and Women's Health: Some Insights on Gender Mainstreaming
}

\author{
KUHELI MUKHOPADHYAY ${ }^{* *}$ and NANDINI DAS ${ }^{2}$ \\ ${ }^{1}$ Assistant Professor, Department of Economics, Sonamukhi College, Sonamukhi, Bankura, India. \\ ${ }^{2}$ Project Personnel, Global Change Programme-Jadavpur University, Researcher, IPCC WG III at \\ Global Center for Environment and Energy, Ahmedabad University, Ahmedabad, India.
}

\section{Abstract}

Climate Change has an overwhelming health impact on all, especially on the women, constituting around $49.58 \%$ of the global population. There is ample literary evidence in support of the claim that a changing climate has a differentiated impact on humanity and that it is not "gender neutral". Climate driven food scarcity, poor air quality, rising temperature and extreme weather events (floods, droughts, heat waves etc.), acute water shortage, increasing incidence of vector borne diseases make the situation all the more dreadful for women in particular. And this vulnerability gets even more critical because of various biological, political, social and cultural factors that historically contributed against women and their empowerment. Though women are reservoirs of indigenous knowledge about how to deal with the aftermath of climatic changes, yet they remain largely untapped. However the importance of gender based climate action plan was long absent in arena of international climate negotiation. It was only in COP7 (2001) where women's involvement in climate action had first caught global attention and subsequently nodal international bodies are working on formulating programmes and appropriate policies for promoting gender balance. However, the progress on this has been limited in comparison to the magnitude of impacts of climatic changes on women's health and hence much more needs to be done on the policy front so as to promote gender equity and women's participation in various adaptation and mitigation policies.

\section{Introduction}

Climate change, with its dire consequences, poses the biggest threat to the humanity (WHO 2003),
(IPCC 2007), (IPCC 2018). However, the impact of climate change is discriminatory for economically and socially disadvantageous groups. Although

CONTACT Kuheli Mukhopadhyay kuheli.gcpju@gmail.com 9 Department of Economics, Sonamukhi College, Sonamukhi, Bankura, India.

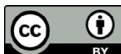

(C) 2019 The Author(s). Published by Enviro Research Publishers.

This is an Open Access article licensed under a Creative Commons license: Attribution 4.0 International (CC-BY).

Doi: http://dx.doi.org/10.12944/CRJSSH.2.2.02 
both men and women are exposed to the adverse health impacts resulting from climatic threats, yet, it is women who are likely to face the greatest brunt of coping with climate related shocks (WHO 2014), (Brody, Demetriades and Esplen 2008). Women are traditionally more vulnerable due to their biological, political, social and cultural status (Chauhan and Kumar 2016), (American College of Obstetricians and Gynecologists 2016). Climate change enhances this vulnerability with recurrence of climatic extreme events like droughts, floods, cyclones and other climatic catastrophe that pose severe threats, even more for women as they act as providers of food, safe water and mental wellbeing for the rest of the family members. While playing these specific roles and responsibilities which involve a high degree of dependence on climate sensitive natural resources like water and food, limited or lack of information in the face of natural disasters are some other factors that compound their hardships in adapting to climate change, as compared to their male counterparts (UNDP 2012), (World Bank 2010), (Dankelman 2010). This scenario is even more acute among women in developing countries. Interestingly, a significant section of the global 1.5 billion population with income of one dollar a day or less, is women (UNFPA 2009). Women especially those who hail from a lower socio-economic backgroundwith low income, limited access to resources, more restricted rights, truncated mobility, and a muffled voice in the process of decision making and policy implementation are around 14 times more susceptible to die from disasters (UNDP 2013).

Women are facing high-risk due to their limited adaptive capacity. Improved adaptation capacity along with higher resilience is inevitable to reduce their vulnerability. The policy needs to focus on climate change along with other socio-economic factors that resulted in vulnerability. Education is often considered as the most effective instrument through which resilience can be developed within a community at large and specifically among women. Literacy rate, one of the most important indicators of developement, is found to be significantly low in least developed countries and even lower among females than their male counterparts, thereby reflecting regional and gender disparities in education. Among the youth population, share of literate women is also not that high, and accounted for only 59 percent (UNESCO Institute of Statistics Global Database, 2019). Inadequate education often leads to lack of awareness and thereby promotes a low adaptive capacity. Women traditionally pose unique knowledge and skills to deal with environmental atrocities (UNDP 2013). If their knowledge and skills can be inculcated then that can definitely be useful for the community at large. The magnitude of the impact of climate change in men and women is different because of their differences in having access to resources, property rights and most importantly in decision making process. In order to ensure food security of the household, women need to spend longer hours and these efforts are never monetized (UNDP 2013). As per World Bank Sources 2019, despite legal protection, globally women do not posses equal land and property rights in most of the countries in the world. This underrepresentation in owning financial assets is one of the key reasons why women suffer more during disasters related to climatic extreme events. Proper representation of women in decision making not only at household but at all levels will ensure a fair distribution of financial assets and economic empowerment which is an important means of reducing this vulnerability.

Given this background, the present article tries to show how adoption of a comprehensive approach with gender integration in existing development and climate policies impact women's health. This article aims to evaluate the impact of a gender based climate policy on women's health by synthesizing evidence from existing literature. Rigorous evaluation of various treaties, reports and resolutions of different international conferences on gender, climate and health has been made in course of the study. Based on this, the commentary is organized as follows. Section 2 of the present commentary makes an attempt to review some literary evidences of how a warming climate impacts women's health conditions. Section 3 highlights some of the global commitments on climate change and gender equality as adopted in various COPs. Section 4 represents how interconnectedness of various Sustainable Development Goals (SDGs) are strengthening adaptive capacity of women in the context of various socio-economic parameters of development with section 5 presenting the concluding remarks. 


\section{Warming Climate and Women's Health: Some Literary Evidences}

Experts worldwide have already cautioned about the disastrous impacts of a warming climate on the health of women in particular. Since female life expectancy is higher compared to that in males, a study conducted by (Neumayer and Plümper 2007) revealed that climatic shocks lower the life expectancy in women. Not only so, it also narrows the gender gap in life expectancy which is prevalent in most of the countries in the world.

All round the world, women, because of higher nutritional needs during childbirth or nutrition, are severely disadvantaged by climate-driven food shortage, thus becoming prone to anemia and malnutrition. Lack of concentration, a blunt memory, and substandard results in exams are some of the outcomes (Jáuregui-Lobera 2014). The situation is all the more grave since women, constituting the bulk of smallholder farmers globally, face professional risks with respect to climate-related crop failure, leading to deteriorated health and abject poverty.

Women are more prone to poor air quality induced diseases that are respiratory and cardiovascular. Anemia and deposition of particulate matter in the lungs are two of the prime causes (Chen, et al., 2005). A correlation between air quality and maternal and child health is also apparent in cases of stillbirth, intrauterine growth restriction, and congenital defects (Šrám, et al., 2005), (Health Effects Institute 2018). Being primarily confined to the domestic space, women have a higher exposure to particulate matter- the source of which can be traced from the use of conventional indoor stoves, widely used for cooking and heating purposes.

Stroke and allied heat related diseases as a direct consequence of rising temperature and extreme heat events, cause greater mortality and morbidity among women. Recently, World Bank (World Bank 2015) pointed out to a study conducted in Columbia which revealed that a month long heat wave has a detrimental impact on the health of pregnant women. It raises the probability of premature births and this can have serious health implications on the future development of babies. Also, incidence of vector borne diseases like malaria is often aggravated by rising temperature. As per WHO estimates
(WHO 2004) malaria which causes 300 million cases of extreme illnesses and is responsible for the death of almost 1 million people per annum impacts pregnant women more than non pregnant ones. During pregnancy women go through various physiological and behavioural changes which aggravate the risk of transmission of malaria which is often looked as an indirect consequence of a warmer climate (Lindsay, et al., 2000).

Globally the number of people affected by tropical storms, cyclones and floods is on the rise. What is more alarming is that the resulting death rate in the age group (20-44) years was 71 per 1000 women in contrast to just 15 per 1000 men(WEDO 2008). Literature (IUCN 2010), (Dankelman 2010), (World Bank 2010) identifies multifarious reasons responsible for this. Restrictive dress codes often limit their quick and hassle free mobility and may prove to be fatal particularly at the time of natural catastrophe. Also, their inherent protective nature, which makes them apprehensive about losing their near and dear ones and precious belongings, makes them unwilling to shift to safer places during storms, cyclones. Even today, coping and basic survival strategies like climbing up a tree, swimming which prove to be crucial in the face of floods and disasters are taught primarily to males. Hence lack of knowledge about survival techniques make women increasingly vulnerable to climate induced disasters. Heavy precipitation and floods pose severe health concerns among women which among others may include mental and psychological stress and risk of malnutrition following reduction in the income levels (FAO 2001), (FAO 2002). Crop failure and subsequent income losses which come hand in hand, following floods and typhoons deteriorate women health further under such a situation(Few and Tran 2010). Floods lead to submergence of tube wells and women are forced to drink polluted and contaminated water, thereby contributing to rising trends of gynaecological issues. Chances of falling down and getting injured among pregnant women while using very slippery roads are high and these force them to remain confined at homes in times of extreme high precipitation and floods.

Another alarming impact of global climate change is that it is going to cause a surge in population 
who somehow manage to survive in water stressed water basins. Estimates reveal that the number may increase from about 1.5 billion in 1990 to 3-6 billion by 2050 (Arnell 2004). In times of shortage of water, women have no other alternative but to rely on water from unsafe sources (including streams and ponds) which in most cases is contaminated. Inadequate sanitation, hygiene, lack of access to safe drinking water often triggers the incidence of water related diseases like diarrhoea which is the second leading cause of death in children under five years old (WHO 2017).Almost half of the population in urban areas of Africa, Asia and Latin America are hapless victims of various water related diseases (UNICEF 2006).

\section{Climate Change and Gender Equality: Commitments Across the Globe}

Though issues like climate change, gender inequality have caught global attention, yet to make substantial progress in tackling these issues deftly, proper formulation, integration and implementation of policies along with constant monitoring has become the need of the hour. When the United Nations Framework Convention on Climate Change was embraced way back in 1992 as the nodal international body to tackle climate change related issues, hardly did it accord any importance to gender dimensions of climate change. However, in contrast to this, Agenda 21, the Rio Declaration, and the Conventions on Biodiversity and on Desertification and Drought made a striking endeavour to highlight women's concerns and suggestions.

It was in 2001, in Marrakesh where the momentous of women's involvement in the UNFCCC was first highlighted. Subsequently it was in COP18 (2012) at Doha, all parties had decided to promote "gender balance". The two main pillars of gender balance under UNFCCC are Lima Work Programme and the GAP. The global network of Gender CC, working for gender equality, women's rights and climate justice came into existence in 2008 . Their main focus was to raise awareness and develop capacity to fight against the dual challenge of gender and climate change by empowering both men and women and this will help to develop comprehensive climate policies by integrating them in mitigation and adaptation actions. At the international level, nodal bodies like IPCC and UNFCCC have slowly started integrating gender dimensions into climate actions (table 1).

International frameworks like the UN Framework Convention on Climate Change (UNFCCC) and United Nations International Strategy for Disaster Reduction (UNISDR) have already integrated a gender perspective into action on climate change. The UNFCCC not only focuses on the development of gender responsive climate policies at different levels, it also emphasizes gender balance and increased participation of women in its processes and in national delegations (Ngetich 2018). UNFCCC decision (2017) calls for a "gender action plan"a comprehensive approach for integration of gender in both mitigation and adaptation strategies through capacity development, technology enhancement, and by enabling strong financial support (Sorensen, et al., 2018). The Sendai Framework for Disaster Risk Reduction 2015-2030, endorsed by the UN General Assembly following the 2015 Third UN World Conference on Disaster Risk Reduction (WCDRR) recognizes the importance of gender-dimensions in disaster risk reduction, calling for inclusiveness and widespread social engagement (UNDRR 2018).

Various conferences on climate change are also recognizing the importance of retaining gender issues in their agenda. In 2014, at COP20 in Lima, a Programme of Action on Gender was established. The objective was to advance implementation of gender-responsive climate policies. Gender equality and empowerment of women in climate action was also appreciated in the Paris Agreement of 2015. A Gender Action Plan was also established in COP23 in 2017 (Ngetich 2018).

The Green Climate Fund, the largest global fund for combating climate change is gradually adopting a more gender-sensitive outlook. It has oflate developed a Gender Policy and Action Plan. In 2015, a Women's Forum was initiated by the Commonwealth. Its objective was to help women raise their voice and bring basic gender related issues to the notice of the leaders and achieve gender equality by 2030 .

The interlinkage between women's health and climate change received a lot more impetus at the 2018 Summit in London. It was in this Summit that 
diplomatic representatives of various countries committed to gearing up action to achieve the targets set under the Paris Agreement. Another noteworthy progress made in this regard is when the Women's Forum called for the Commonwealth to incorporate gender in addressing climate change related issues.
From the above, thus, it becomes evident that some progress has already been made in tackling the complex issues of climate change, women and their health implications, nonetheless, a lot more needs to be done to boost up the strength of the small and vulnerable states.

\section{Table 1: Introduction of Gender Perspective into Climate} Negotiations: A summary from Recent COPs

\begin{tabular}{|c|c|c|c|}
\hline $\begin{array}{l}\text { International } \\
\text { Conventions }\end{array}$ & Year & & Key Highlights \\
\hline $\begin{array}{l}\text { COP } 20 \\
\text { Lima, Peru }\end{array}$ & 2014 & $\bullet$ & $\begin{array}{l}\text { To promote gender balance in climate policy a two year programme } \\
\text { was introduced } \\
\text { Promotion of gender mainstreaming coupled with women's active } \\
\text { involvement in various climate talks by roping in different stakeholders } \\
\text { Appointment of a senior gender focal point so as to facilitate smooth } \\
\text { implementation of the programme } \\
\text { Provision of a budget designated to fulfill the above objectives }\end{array}$ \\
\hline $\begin{array}{l}\text { COP } 21 \\
\text { Bourget, } \\
\text { Paris }\end{array}$ & 2015 & $\bullet$ & $\begin{array}{l}\text { To ensure a gender sensitive approach in tackling climate change } \\
\text { issues, concrete actions to be taken to engage women in } \\
\text { formulating climate change policies. }\end{array}$ \\
\hline $\begin{array}{l}\text { COP } 22 \\
\text { Marrakesh, } \\
\text { Morocco }\end{array}$ & 2016 & • & $\begin{array}{l}\text { Extension of Lima Work Programme for three more years i.e. till } 2019 \\
\text { Inclusion of gender dimensions in each and every aspect of climate } \\
\text { policy like mitigation, adaptation etc. } \\
\text { To boost up implementation of gender related decisions and directives } \\
\text { pertaining to UNFCCC, subsidiary bodies for implementation were } \\
\text { requested to formulate a proper gender action plan } \\
\text { Subsidiary Body for Implementation were requested "to develop a } \\
\text { gender action plan in order to support the implementation of gender- } \\
\text { related decision and mandates under the UNFCCC process" }\end{array}$ \\
\hline $\begin{array}{l}\text { COP } 23 \\
\text { Bonn, } \\
\text { Germany }\end{array}$ & 2017 & • & $\begin{array}{l}\text { Approval of a Gender Action Plan (GAP) } \\
\text { GAP promulgates implementation of gender-related decisions along } \\
\text { with women's full, equal and meaningful participation at all levels and } \\
\text { also promotes gender-responsive climate policy }\end{array}$ \\
\hline $\begin{array}{l}\text { COP } 24 \\
\text { Katowice, } \\
\text { Poland }\end{array}$ & 2018 & 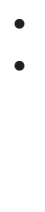 & $\begin{array}{l}\text { Parties reviewed Lima Work Programme on gender } \\
\text { UN Women carried forward gender related issues through supporting } \\
\text { Parties ' initiatives like the "For All Coalition", (led by the Government } \\
\text { of Costa Rica), and the Declaration on Gender Equality and Climate } \\
\text { Change }\end{array}$ \\
\hline
\end{tabular}

Source: Adopted from (Gender CC: Women for Justice 2019), (UN Women 2018) 
Climate Change and Gender Equality: In Light of Sustainable Development Goals

It is accepted across the nations that there is an overlapping zone between climate and development goals. Access to education, affordable healthcare, safe drinking water, improved disaster relief- all these are instrumental in developing resilience against climate change which are also the key development objectives (Buchner, et al., 2013). In 2015, members of the United Nations have adopted 17 global goals known as Sustainable Development Goals (SDGs) as a blueprint to achieve better development standards for all by 2030. Out of these seventeen SDGs, there are three separate goals which specifically target health and well being (goal 3), gender equality (goal 5) and climate action (goal 13). As this interaction is multidimensional, SDG framework provides an integrated approach to address these issues in connection with other developmental issues. This framework provides a comprehensive opportunity to reduce climate induced health impacts on women in an integrated way. Goal 1 (no poverty) renders equal rights of women in economic resources and achieving this goal is beneficial to build resilience against various vulnerabilities including physical and environmental. Goal 2 (zero hunger) talks about providing sufficient food to all, especially to women and children. Ensuring proper nutrition to women is again a way to develop resilience against climate vulnerability and also strengthen the capacity of adaptation in the face of extreme events and climate change in general. Education (goal 4) is an important mean to reduce gender disparity and thereby strengthen participation of women in decision making processes. One of the important set backs of climate change is shortage of water which is again linked to poor hygiene and sanitation and associated health impacts. As mentioned earlier, women are more vulnerable to this kind of situation due to their socio-economic and political status. Now clean and affordable water and adequate and equitable sanitation (goal 6 ) for all will act as an enabler to improve resilience against climate change, especially for the women. Against these basic challenges of poverty, hunger, education and water, a sustainable per capita economic growth (goal 8) through meaningful employment can also act as a source of women empowerment and thereby improve participation of women in decision making processes which will in turn improve their resilience against any sort of vulnerability. Apart from these goals other goals are also connected to this issue in an indirect way. Reduction of overall economic inequality (goal 10) in a gender sensitive way is also helpful in building up resilience. Access to clean energy (goal 7) will help to increase productivity of population who lacks them and will help to achieve social sustainability by reducing inequality and by improving individual and social wellbeing. Access to safe public spaces through a sustainable urban development (goal 11) is also important to achieve an overall development.

The interaction between health and climate change from a gender perspective is indeed a complex and layered issue. Hence it is important to look into these perspectives as well in the context of other developmental challenges as it is difficult to achieve any solution in isolation.

\section{Conclusion}

Climate change impacts women severely. In the existing socio-cultural context, the interface of gender mainstreaming in the discourse of climate change is critical. Climate related health impacts are leading to double marginalization of women as they are already vulnerable especially in developing countries. Poverty aggravates discrimination based on gender and this leads to increased health issues for women in the face of climate change-thereby forming an inevitable nexus. Lack of accessibility to sustainable health practices, training and awareness are leading to even more vulnerable situation for women. Since the role of women in societal response to climate change cannot be ignored, hence, their participation and engagement at all levels is crucial in evolving sustainable solutions to their health threats. To achieve such sensitized policies, it is imperative to analyze the distinct capabilities of both men and women to deal with adaptation, mitigation options and this can be achieved by procuring and analyzing sex disaggregated data on women's health because of a changing climate. Imparting appropriate training to women will equip them with certain life saving skills (like swimming etc.) which can at times become important survival and adaptation strategies. The government, non-governmental organizations and other stakeholders can be instrumental in arranging such training programmes for women at the community level. There is an urgent need for 
such gender-sensitive vision to be reflected not only in state policies, but it is equally important to incorporate gender sensitive perspectives and policies at the global, national and local levels of climate discourse. Herein lies the importance of gender mainstreaming which has already been recognized by the UNFCCC. It is equally important to create cross-national networks that facilitate sharing of local experiences and knowledge. This will pave the way to identify gaps and understand challenges in formulating proper gender based coping mechanisms which will be of supreme importance not only to protect women's health but also in channelizing their monumental prospects to mitigate, adapt to, and reciprocate to a changing climate. Inclusive and participative decision making that will bring together the experiences faced by women is thus the inevitable cornerstone to increase their adaptive capacity and build up resilience to climate change.

\section{Acknowledgement}

Nandini Das duly acknowledges Global Change Programme- Jadavpur University for providing financial and infrastructural support to carry out her research work.

\section{Funding}

The author(s) received no financial support for the research, authorship, and/or publication of this article.

\section{Conflict of Interest}

There is no conflict of interest for this article.

\section{References}

1. American College of Obstetricians and Gynecologists. "Climate Change and Women's Health". 2016 pp.283-293

2. Arnell, Nigel W. "Climate Change and Global Water Resources: SRES Emissions and Socio-economic Scenarios". Global Environmental Change (Elsevier) 14, no. 1 (2004) pp.31-52

3. Brody, A, J Demetriades, and E Esplen. "Gender and Climate Change: Mapping the Linkages." UK: BRIDGE, Institute of Development Studies (IDS). 2008 https://siteresources.worldbank.org/ Extsocialdevelopment/Resources/DFID_ Gender_Climate_C hange.pdf (accessed July 2019)

4. Buchner, B., Herve-Mignucci, M., Trabacchi, C., Wilkinson, J., Stadelmann,M., Boyd, R., et al., (2013). The Global Landscape of Climate Finance2013. Climate policy Initiative

5. Chauhan, N. B., and V. H. Kumar. "Gender Responsive Climate Change Strategies for Sustainable Development". Productivity 57, no. 2 (2016) pp 182-186

6. Chen, LH, SF Knutsen, D Shavlik, WL Beeson, F Petersen, and M Ghamsary. "The Association Between Fatal Coronary Heart Disease and Ambient Particulate Air Pollution: Are Females at Greater Risk?" Environmental Health Perspectives, 2005 pp 1723-1729
7. Dankelman, I, ed. "Gender and Climate Change: An Introduction". London: Earthscan, 2010

8. FAO. "Gender and Nutrition". 2001. http:// www.fao.org/

9. The State of Food Insecurity in the World. 2002. http://www.fao.org/

10. Few, R, and PG Tran. "Climatic Hazards, Health Risk and Response in Vietnam: Case Studies on Social Dimensions of Vulnerability". Global Environmental Change (Elsevier), 2010 pp 529-538

11. Health Effects Institute. "Burden of Disease Attributable to Major Air Pollution Sources in India: Summary for Policy Makers". 2018

12. IPCC. "Industry, settlement and society. In: Climate Change 2007: Impacts, Adaptation and Vulnerability. Contribution of Working Group II to the Fourth Assessment Report of the Intergovernmental Panel on Climate Change". 2007

13. IPCC. "Special Report:Global Warming of 1.5드, Summary for Policy Makers". 2018

14. IUCN. Climate Change and Gender Factsheets. 2010. https://www.iucn.org/ content/climate-change-and-genderfactsheets (accessed July 2019)

15. Jáuregui-Lobera, I. "Iron Deficiency and Cognitive Functions". Neuropsychiatric Disease and Treatment, 2014 pp 2087-2095 
16. Lindsay, S, J Ansell, C Selman, V Cox, K Hamilton, and G Walraven. "Effect of Pregnancy on Exposure to Malaria Mosquitoes". Lancet, 2000.

17. Neumayer, E, and T Plümper. "The Impact of Catastrophic Events on the Gender Gap in Life Expectancy, 1981-2002". Annals of the American Association of Geographers 97, no. 3 (2007)

18. Ngetich, S. Gender and Climate Change Where Are We and What Next? 2018. http:// thecommonwealth.org/blog/gender-andclimate-change-\%E2\%80\%93-where-arewe-and-what-next (accessed July 2019)

19. Sorensen, C, V Murray, J Lemery, and J Balbus. "Climate Change and Women's Health: Impacts and Policy Directions". PLOS Medicine 15, no. 7 (2018)

20. Šrám, RJ, B Binková, J Dejmek, and M Bobak. "Ambient Air Pollution and Pregnancy Outcomes: A Review of the Literature". Environmental Health Perspectives, 2005 pp375-382

21. UNDP. "Gender and Climate Change:Asia and the Pacific, Policy Brief". 2013

22. UNDP. "Overview of Linkages Between Gender and Climate Change". 2012

23. UNDRR. Sendai Framework for Disaster Risk Reduction. 20182018.

24. https://www.unisdr.org/we/coordinate/ sendai?framework (accessed July 2019)

25. UNFPA. "State of World Population 2009:
Facing a Changing World:Women, Population and Climate". 2009

26. UNICEF. "Water, Sanitation and Hygiene Annual Report". 2006

27. UNICEF. "Literacy among youth is rising, but young women lag behind". 2019. 22112019. $<$ https://data.unicef.org/topic/education/ literacy/>

28. WEDO. "Gender, Climate Change, and Human Security: Lessons from Bangladesh, Ghana and Senegal". Women's Environment and Development Organization, 2008

29. WHO. "Climate Change and Human Health -Risks and Responses. Summary". 2003

30. WHO. "Gender, Climate Change and Health". 2014

31. WHO. "The Global Burden of Disease: 2004 Update". 2004

32. WHO. "Diarrhoeal Disease." 2017

33. World Bank. " Social Dimensions of Climate Change". 2010

34. "Climate Change Impacts People Who are not Born Yet". 2015 https://www.worldbank.org/ en/news/feature/2015/04/21/climate-changehealth-at-birth (accessed September 2019)

35. World Bank. "Women in Half the World Still Denied Land, Property Rights Despite Laws". 2019. 2211 2019. <https://www.worldbank. org/en/news/press-release/2019/03/25/ women-in-half-the-world-still-denied-landproperty-rights-despite-laws> 